\title{
The effect of the type of fixators reinforcement on strength and deformation characteristics of reinforced concrete
}

\author{
Evgenij Borisyuk ${ }^{*}$ \\ Moscow State University of Civil Engineering, Yaroslavskoe shosse, 26, Moscow, 129337, Russia
}

\begin{abstract}
Rebar fixators of various types (plastic and concrete) became widespread with manufacturing of building structures of precast and monolithic reinforced concrete in order to fix steel reinforcement cage in strictly design position and to exclude the probability of its displacement during concreting. Such sufficiently rigid fixing is necessary for the following reliable operation of the structure in the building, as well as for the preservation of steel reinforcement which protected by a necessary layer of concrete from corrosion. Information available in the literature does not allow us to judge about the effects that different types of fixators apply to exploitative properties (such as strength and crack resistance) of reinforced concrete. The experiments, according to the accepted method, showed that these characteristics are slightly worse for the samples with plastic fixators and fixators made of low grade concrete than for the samples without fixators or fixators made of high grade concrete. On the base on the research results it becomes possible to substantiate the distinction between the areas of application of plastic and concrete fixatives
\end{abstract}

\section{Introduction}

Ensuring of reliability and durability of building structures made of reinforced concrete, especially those working in adverse conditions (high humidity, saline water, etc.), necessitates the use of guaranteed methods and manufacturing modes of these structures. A prerequisite for manufacturing high-quality reinforced concrete products is the fixation of the steel reinforcement cage when concreting in a strictly design position, denying any probability of rebar frame displacement. Such a sufficiently rigid fixing is necessary for the subsequent reliable operation of the construction in the structure (ensuring the calculated stress distribution without the occurrence of possible local internal defects and cracking), as well as for the preservation of steel reinforcement protected by the necessary layer of concrete from corrosion. This task is performed by special embedded parts, which are called rebar fixators. It is considered that the main function of rebar fixators is to provide a protective layer of rebar against possible corrosion due to the harmful effects of corrosive environment, but the role of retainers is not limited to this. While fixing rebar in the form, fixators allow the concrete mixture to be evenly distributed around the rebar during the

*Corresponding author: eab2019@mail.ru 
molding process, further contributing to maximum adhesion of the concrete to the rebar and, as a result, ensure the ability of the structure to work in design modes. Therefore, the term "fixators for protective layer of rebar in concrete" does not fully reflect their function. The task of protecting rebar in concrete from the harmful effects of the external environment is quite important and requires a special assessment of the quality of existing and proposed fixators $[1 ; 12 ; 14]$. Currently, there is very little information about nature and degree of influence of the type and quality of fixators onto exploitative characteristics of structures made of reinforced concrete.

\section{Theoretical Basis}

The high rates of construction, the development of monolithic house building and the increased requirements for prefabricated concrete products led to an increase in the need of rebar fixtures, which production has increased significantly in recent years $[3 ; 6]$. Plastic fixators made of PVC, HDPE, PP, etc. are now widely used. Fixators have a different shape and purpose. By their use, the fixators are divided into three categories: fixators for installation on vertical rebar; fixators for installation on horizontal rebar; fixators for installation into the formwork with concrete total thickness fixation.

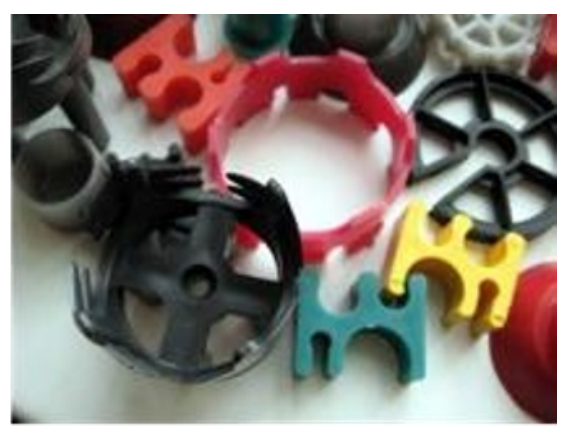

Fig. 1. Plastic fixators.

The use of plastic clamps is expedient and justified in designs that are less susceptible to the harmful effects of the external environment and are outside the zone of high loads. This is explained by the fact that the adhesion of cement and, consequently, of concrete to plastics is low. The contact zone in this case can serve, firstly, as a source of local defects and cracks under the action of loads at the location of the plastic fixators, and secondly, since the supporting part of the fixators reaches the surface of the structure, through it "aggressive environment" it can sufficiently freely penetrate along the "concrete-fixer" boundary to the reinforcement, causing its corrosion. Plastic fixators can be recommended for reinforced concrete structures operating in air-dry conditions with low internal stresses. For structures operating under the influence of corrosive environments and in complex stress-strain fields, the use of plastic fixators for fixing rebar in concrete products is unacceptable. Such structures include supporting elements of bridges, elements of high-rise buildings, tubing, tanks, etc. Such structures require fixators made of materials having high adhesion and chemical affinity with the main material of the product: asbestos cement, high-strength fine-grained concrete with various mineral and chemical additives, etc.

In this case, the border of the fixator and concrete is conditional, since the crystals of new growths of hardening cement product and fixator grow together over time and create a dense and fairly strong connection. The main function of fixator is to clearly fix the rebar in the design position and thereby ensure the design characteristics of the structure. 
Fixators make significant changes to the reinforced concrete structure, related to their type and the type of material from which they are made, being in fact a defect in the structure of concrete:

- the modulus of elasticity of the plastic is almost an order of magnitude lower than that of concrete $\left(3,0 \times 10^{3}\right.$ and $\left.30 \times 10^{3} \mathrm{MPa}\right)$ and therefore, when tensile stresses occur in the contact zone, the plastic fixator becomes a stress concentrator, which results in earlier cracks occurrence;

- low adhesion of concrete to plastic (almost zero) also reduces crack resistance of concrete;

- linear thermal expansion coefficients for plastics and concrete differ significantly $\left(10 \times 10^{-5}{ }^{\circ} \mathrm{C}^{-1}\right.$ for plastics and $1 \times 10^{-5}{ }^{\circ} \mathrm{C}^{-1}$ for concrete) and therefore, when using heat treatment of concrete, the temperature cracks may form when cooling the structure at the "concrete-fixator" boundary.

Concrete fixators are small embedded parts of fine-grained concrete, having a special attachment to the rebar in the form of clothespins, springs, clamps, latches or simply knitting wire. The shape of the latches is not regulated; it can be diverse and depends largely on the method of manufacture (extrusion, vibration molding, casting, etc.) and on the conditions of their subsequent use. The main geometrical parameters controlled during the manufacturing process are the diameter of the rebar with which the fixator can be used and the distance from the rebar to the base of the fixator support part - which determines the thickness of the protective layer of concrete. The technical characteristics of concrete for fixators, such as: strength, water resistance, corrosion resistance, etc., should correspond to the technical characteristics of the concrete of the main product. It is also necessary that the area of the support part of the fixators be minimal: pinpoint or linear, so that the fixator from the outside is almost completely covered with concrete. In order to identify the nature and degree of influence of fixators of different types in concrete and reinforced concrete on its design characteristics, an experiment was planned and staged in the factory and laboratory conditions. In the course of the work, the influence of plastic asterisk fixators was compared (Fig.2), as well as concrete fixators of complex shape made of concrete of different strengths (Fig.3).

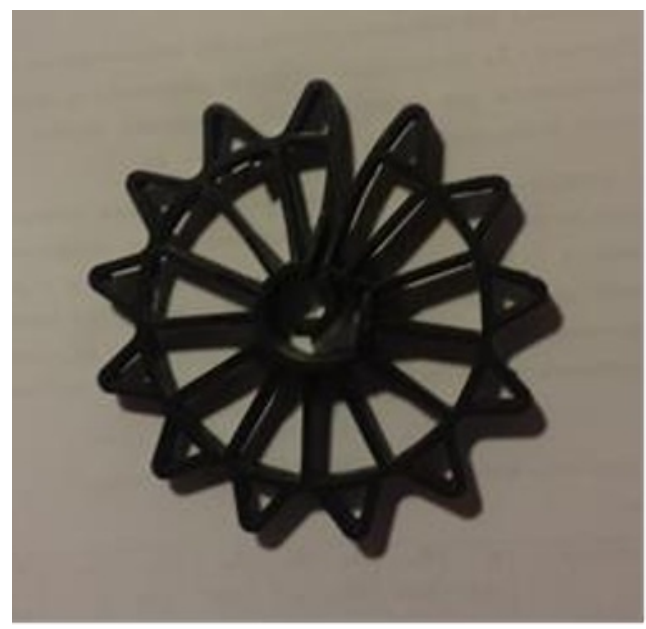

Fig. 2. Asterisk shape plastic fixator.

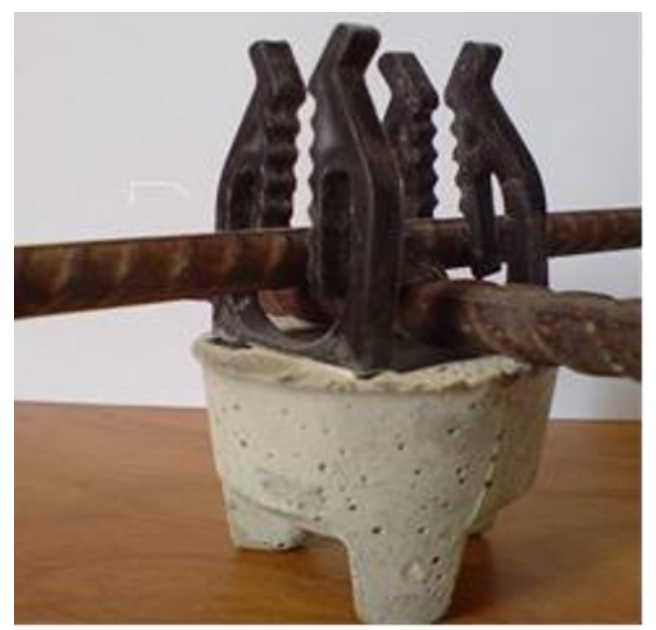

Fig. 3. Concrete retainer. 


\section{Results and Discussion}

In the course of the work, samples-beams with a size of $150 \times 150 \times 600 \mathrm{~mm}$ and cubic samples with a size of $150 \times 150 \times 150 \mathrm{~mm}$ were made. In total, five batches of samples were manufactured:

1. Reference samples-beams and cubes, unreinforced and without fixators.

2. Reference samples-beams reinforced in the lower belt (fittings with a diameter of 14 $\mathrm{mm}$ ) without fixators with a protective layer of concrete $35 \mathrm{~mm}$.

3. Samples-beams reinforced (similar to paragraph 2) with plastic fixators and cubes with plastic fixators molded in the body of concrete in the working position, but without reinforcement.

4. Samples-beams reinforced (similarly to p.2) with concrete fixators and cubes with concrete fixators with a strength of $20.0 \mathrm{MPa}$, molded in the concrete body in the working position, but without reinforcement.

5. Samples-beams reinforced (similar to p.2) with concrete fixators and cubes with concrete fixators with a strength of $40.0 \mathrm{MPa}$, molded in the concrete body in the working position, but without reinforcement.

The strength of concrete fixators was determined by indirect estimates (by hardness): in one part of the fixators it did not exceed $20.0 \mathrm{MPa}$, which is $30 \%$ less than the design strength of concrete samples, in the other part of the fixators, the strength was about 40.0 $\mathrm{MPa}$, which is $30 \%$ higher than designed strength of concrete samples.

Each batch included 3 sample beams and 3 sample cubes. All samples were made at the same time, from a concrete mix of one batch. The composition of concrete with the ratio C: P: Y: $\mathrm{B}=1: 2.7: 4.0: 0.67$ on Portland cement M500 (D0). The composition used in the experiment corresponded to the calculated composition of concrete in strength class B22.5 (M300). Granite crushed stone and quartz sand with a particle size module of $\mu .=1.5$ were used as aggregates. The prepared concrete mix corresponded to the mobility of P2 (concrete slump test result $=5-9 \mathrm{~cm}$ ), which was provided by the addition of "Pozzolith MR 55". Manufactured samples were heat-treated. After stripping, the samples were hard for 68 days in natural air-wet conditions.

Then the samples were tested for axial compression and tensile bending in accordance with the method proposed in work $[2 ; 4 ; 5]$ :

1. The main strength characteristics of concrete are determined: cubic strength - R, prism strength - Rb.

2. The limits of tensile strength at bending were determined - $\mathrm{R}_{\mathrm{tf}}$ of reference and reinforced beam samples without fixators and with fixators when monitoring the moment of cracking [2].

3. Water resistance is determined - W, on samples-cubes without fixators and with fixators of different types.

The deformative characteristics of the samples-beams were determined: the modulus of elasticity - $\mathrm{Eb}$, the transverse strain coefficient - $\mathrm{vb}$, the limiting relative deformation at the moment of crack formation $-\varepsilon_{\mathrm{tf}}$, the relative deformation at the moment of fracture $-\varepsilon_{\mathrm{b} 0}$.

During the tests to determine the prismatic strength and tensile strength in bending, the increase in the load was carried out in stages, with a five-minute exposure to the stage, at the same time, in order to measure the ultimate tensile strains, beacons on the basis of 15 $\mathrm{cm}$ with indicators of the hourly type with a division price of $0.001 \mathrm{~mm}$ were attached to the zone of maximum tensile stresses (Fig.4). 


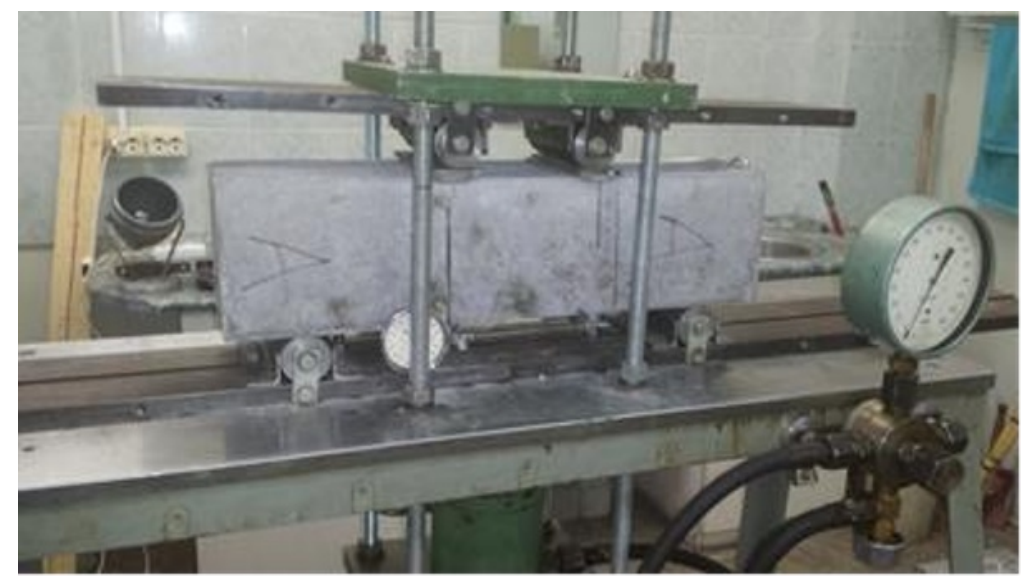

Fig. 4. Bending tensile test on samples-beams.

The results of the tests are presented in table 1.

Table 1. Physico-mechanical characteristics of reinforced concrete with fixators various type.

\begin{tabular}{|l|l|l|l|l|l|l|l|l|l|}
\hline № & Type of sample & $\begin{array}{l}\mathbf{R} \\
\mathrm{MPa}\end{array}$ & $\begin{array}{l}\mathbf{R}_{\mathbf{b},} \\
\mathrm{MPa}\end{array}$ & $\begin{array}{l}\mathbf{R}_{\mathbf{t f}}, \\
\mathrm{MPa}\end{array}$ & $\begin{array}{l}\mathbf{E}_{\mathbf{b}} \\
\mathrm{x} 10^{3} \\
\mathrm{MPa}\end{array}$ & $\begin{array}{l}\mathbf{\varepsilon}_{\mathbf{t f}} \\
\mathrm{x} 10^{-5}\end{array}$ & $\begin{array}{l}\mathbf{E}_{\mathbf{b}} \\
\times 10^{-5}\end{array}$ & $\mathbf{v}_{\mathbf{b}}$ & $\mathbf{W}$ \\
\hline 1 & $\begin{array}{l}\text { Reference s. } \\
\text { (unreinforced) }\end{array}$ & 50.7 & 41.7 & 4.1 & 34.3 & 19.5 & 228 & 0.213 & 8 \\
\hline 2 & $\begin{array}{l}\text { Reference s. } \\
\text { (reinforced) }\end{array}$ & - & - & 4.7 & - & 22.8 & - & - & - \\
\hline 3 & $\begin{array}{l}\text { With plastic } \\
\text { fixator }\end{array}$ & 44.5 & - & 3.7 & - & 15.4 & - & - & 2 \\
\hline 4 & $\begin{array}{l}\text { With M200 } \\
\text { concrete fixator }\end{array}$ & 45.3 & - & 3.6 & - & 14.5 & - & - & 4 \\
\hline 5 & $\begin{array}{l}\text { With M400 } \\
\text { concrete fixator }\end{array}$ & 49.2 & - & 4.6 & - & 20.6 & - & - & 8 \\
\hline
\end{tabular}

The test results show that at the time of testing, the compressive strength $\mathrm{R}$ of concrete was $50.7 \mathrm{MPa}$, which significantly $(60 \%)$ exceeded the calculated mark strength corresponding to 28 days of normal hardening, due to the longer period of hardening (68 days) and higher strength concrete fixers 1.2 - 2.5 times. At the same time, the strength of cube samples with plastic fixators and fixators made of concrete with a strength of 20.0 $\mathrm{MPa}$ was $12-14 \%$ lower and amounted to $44.5 \mathrm{MPa}$ and $45.3 \mathrm{MPa}$, respectively. When testing cubes with fixators made of concrete with a strength of $40.0 \mathrm{MPa}$, a slight decrease in strength was observed - 49.2 MPa.

Analysis of the results of the experiment shows a high imperfection of the structure of concrete $n_{t f}=R_{b} / R_{t f}$ [4], reaching an index $=10.2$. When using fixators, the structure's defectiveness increases and amounts to: 11.6 for plastic fixators, 11.7 for concrete (20.0 $\mathrm{MPa}$ ). However, the use of concrete fixators with a strength of $40.0 \mathrm{MPa}$ contributes to a decrease in the structure's defects to 10.3 , that is close to the structure of concrete without 
fixators.

The axial tensile strength, calculated with an index $=1.7$ [4], corresponded to the value of $2.41 \mathrm{MPa}$ and was close to the values shown in the graph presented in Figure.
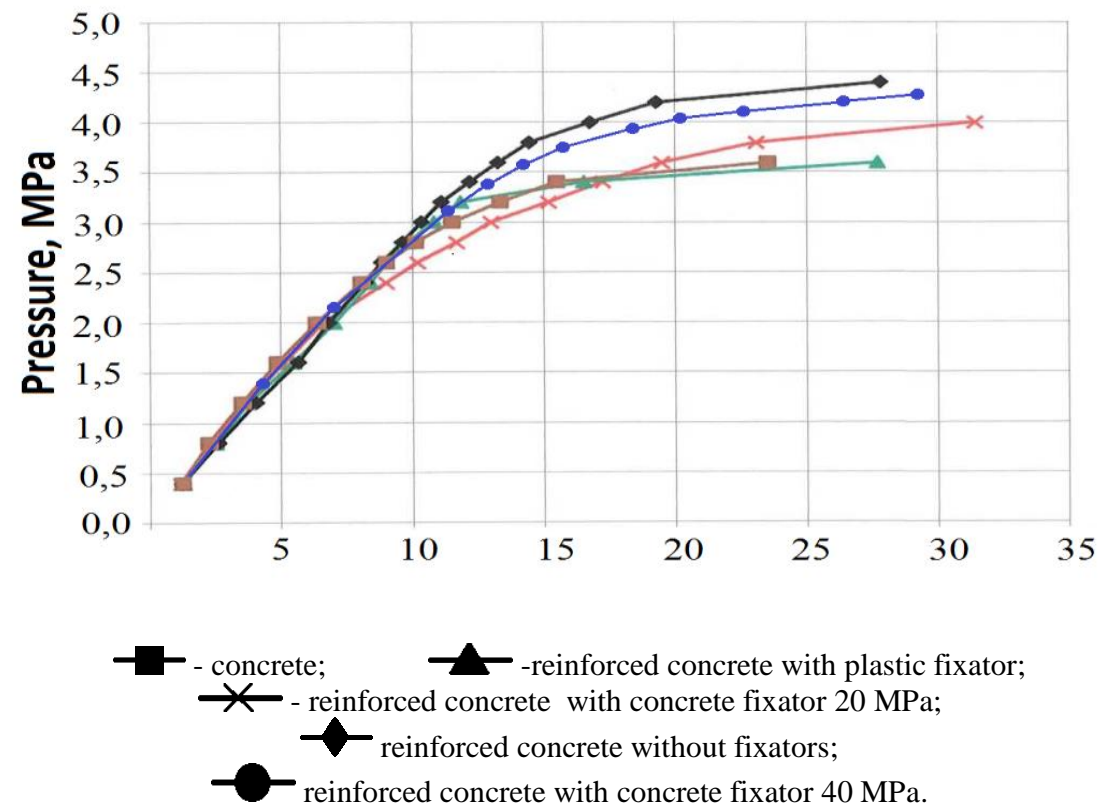

Fig. 5. Diagrams of deformation of concrete and reinforced concrete in tensile bending.

Significant deviations from the linearity of deformation occur in the area from 2.4 to 2.8 $\mathrm{MPa}$, which coincides with the calculated value. This stress level corresponds to the ultimate tensile strain of $8 \div 9 \times 10^{-5}$. It should be noted that in this case the characters of the stress curves of the samples-beams with reinforcements without fixators and with fixators made of concrete (40.0 MPa) are close and exceed the readings of the samples without reinforcement, as well as with plastic and concrete $(20.0 \mathrm{MPa})$ fixators. The same is true of the magnitude of the ultimate deformability corresponding to the moment of cracking.

In similar way value of the ultimate deformability correspond to the moment of cracking. Samples with concrete fixators with a strength of $20.0 \mathrm{MPa}$ has lower characteristics than samples with concrete fixators with a strength of $40.0 \mathrm{MPa}$ which confirm a significant role in the structural strength of concrete fixators. When the strength of the concrete retainer is less than the strength of the concrete structure, the retainer can also be considered as a defect - stress concentrator. The presence of clamps very significantly affected the process of cracking. Thus, the moment of cracking in samples with plastic clamps decreased by $19.6 \%$, and with concrete (20.0 MPa) clamps by $21.7 \%$, compared to reinforced samples without clamps or with clamps made of concrete 40.0 MPa. When the strength of the concrete fixator is less than the strength of the concrete structure, the fixator can also be considered as a defect - stress concentrator. The presence of fixators very significantly affected the process of cracking. Thus, the moment of cracking in samples with plastic fixators decreased by $19.6 \%$, and with concrete (20.0 MPa) fixators by $21.7 \%$, compared to reinforced samples without fixators or with fixators made of concrete 40.0 MPa. At the same time, for samples with plastic and concrete (20.0 MPa) fixators, the crack resistance was even lower than for samples without reinforcement by 9.85 and $12.2 \%$, respectively.

Checking the water resistance of the samples also confirmed the negative role of plastic and concrete fixators with low strength $[10 ; 11]$. At the same time, the use of concrete 
fixators with a strength close to the strength of the concrete structure, practically does not affect water resistance.

\section{Conclusions}

1. From the results of the experiment we see that choice of the fixator in the assessment of crack resistance should be done taking into account the type of material from which it is made.

2. It was confirmed that the use of plastic fixators in the reinforcement of concrete, leads to a decrease in crack resistance by $20-22 \%$, which must be considered in the design of precast and monolithic reinforced concrete structures.

3. When using concrete fixators the most important factor is the strength of concrete fixators. The test results showed that the use of concrete fixators with strength less than strength of the concrete structure by 2.5 times, also leads to a decrease in crack resistance by $20 \%$. Therefore, for structures operating under conditions of high aggressiveness of the environment, use of concrete fixators with strength less than the strength of the structural concrete is unacceptable.

4. Given the fact that the ultimate tensile stresses in concrete are low enough, it is necessary to take a more responsible approach to the selection of reinforcement fixators and conduct their experimental verification with an assessment of their impact on cracking.

5. Water resistance of reinforced concrete structures depends on the type of fixators and is significantly reduced when using plastic fixators and concrete fixators with strength lower than that of the concrete structure.

\section{References}

1. SP 28.13330 - 2012. Protection of building structures against corrosion (2012)

2. GOST 10180 - 2012 Concretes. Methods for determining the strength of the control samples (2012)

3. I. Bezgodov, E. Borisyuk, M. Kozhevnikov, V. Sviridov. Concrete technology. 7-8, 21 (2012)

4. I. Bezgodov. Concrete and reinforced concrete. 2, 2 (2012)

5. I. Bezgodov. Concrete and reinforced concrete. 5, 9 (2015)

6. V. Tramboveckij. Concrete and reinforced concrete. 3, 25 (2001)

7. I. Vasilev, A. Bejvel, A. Podvalnyj. Concrete and reinforced concrete. 5, 20 (2001)

8. E. Borisyuk, O. Largina. Nanosystems in construction and production of construction materials. 1, 38 (2007)

9. Y. Chistov, E. Borisyuk, R. Levshunov. Herald of the electric power industry. 1, 53 (1996)

10. A. Antonyan. Concrete technology. 9-10, 29 (2017)

11. GOST 12730.5-84 Concretes. Methods for determining water resistance (Appendix 4)

12. L. Korotkov. Concrete technology. 5-6, 42 (2017)

13. G. Pshenichnyj. Concrete technology. 9-10, 56 (2015)

14. O. Bajdin, E. Glagolev. The Bulletin of BSTU named after V.G. Shukhov. 3, 53 (2012) 